Research Paper

\title{
Segmentation and Classification of Indian Domestic Tourists \\ - A Tourism Stakeholder Perspective
}

Saibal Dutta

Vinod Gupta School of Management

Indian Institute of Technology

Kharagpur, India

E-mail: saibal.13@gmail.com

SujOY BHATTACHARYA

Vinod Gupta School of Management

Indian Institute of Technology

Kharagpur, India

Kalyan Kumar Guin

Vinod Gupta School of Management

Indian Institute of Technology

Kharagpur, India 


\section{About the author}

Saibal Dutta is presently working as a Senior Lead in the field of telecom data analytics at Tata Communication Ltd, India. He holds a master's degree in Electronics and communication from the National Institute of Technology, Rourkela, India, and is pursuing his Ph.D in Data mining and Machine learning at Indian Institute of Technology, Kharagpur, India. He has many publications in reputed international journals and has written books on Image processing and Machine leaning. His areas of expertise include data mining, machine learning, image processing, and business consultation.

Sujoy Bhattacharya is an associate professor at Vinod Gupta School of Management, Indian Institute of Technology, Kharagpur, India. He received his Ph.D in marketing from ABV-Indian Institute of Information Technology \& Management, Gwalior, India. He has teaching and research experience at Mudra Institute of Communications Ahmedabad, Goa Institute of Management, and S.P. Jain School of Global Management, Singapore before joining the current workplace.

Kalyan Kumar Guin received his Ph.D in Qualitative Modeling and marketing from Indian Institute of Management, Bangalore. He is currently the dean of Vinod Gupta School of Management at Indian Institute of Technology, Kharagpur, India. He has actively participated in real-life problem-solving in the business field through routine consulting practice for reputable sector industries in India and abroad. Prof. Guin has a special interest in research related to Qualitative Modeling of Strategic Issues in Management. 


\section{Abstract}

The rapid growth of the domestic tourism sector has open immense opportunity that has not been marketed properly so far by the Indian government. In this regard, tourism stakeholders are the primary responsible for the implementation of successful destination marketing. Till date, Tourism research has been focused on stakeholder involvement and their complex relationship in destination marketing, but never appreciates their view point and direct involvement in the market segmentation process. In this paper, the concept of stakeholder theory has been successfully utilized the problem of market segmentation and classification of the Indian domestic tourism sector. The research approach followed in this work in qualitative and quantitative in nature where in-depth interviews of three key stakeholders are conducted for assessment of variable selection and in the consecutive step, analysis was performed on 459 complete primary data collected through a self-administered survey of potential tourist to the study area using factor-cluster segmentation approach. The result suggests three, five and six cluster solution possible for accommodation service provider, tour operator, and tourism policy maker respectively. The result of the segmentation was then further used to train and develop various efficient classifier models, namely, Recursive Partitioning Trees, Pruning Recursive Partitioning Tree, Conditional Inference Tree, K-Nearest Neighbor Classifier, Naive Bayes Classifier, Neural Network (Radial basis function network and Multilayer Perceptron), Support Vector Machine, Linear Discriminant Analysis and Random Forest. The study indicated that the Support Vector Machine (SVM) classifier model achieved the highest accuracy of $90.71 \%, 86.43 \%$ and $89.29 \%$ for accommodation service providers, tour operators and tourism policy makers respectively compared to those given by the above mentioned methods. The results hold substantial implications to the stakeholders' perspective of successful destination marketing and positively contributed to formulating useful policy, planning and strategy buildup.

Keywords: Stakeholder, Indian Tourism, Segmentation, Classification, Factor Analysis, Domestic Tourism, Destination Marketing

\section{Introduction}

Tourism sector has been recognized as one of the leading players in the global industrial domain, which aids to accelerate the national economies through the developmental process, highlights and conserves the cultural heritage and, acts as a bridge towards the global harmony and peace. In the recent years, the tourism industry outperformed to prosper the entire economy in a wider aspect, flourishing rapidly as compared to other industries such as manufacturing, financial services and retail. Tourism industry is proceeding towards to achieve the breakthrough, and to be among one of the world's largest industries with growth rate more than four percent per annum during the last twenty years (Source: World Travel and Tourism Council, http://www.wttc.org). Most of the Asian and European countries have recognized the tourism industry, as one of the highest GDP contributors and a prospective solution to pinpoint the national issues, like poverty, unemployment, creating new service opportunities, fostering entrepreneurship, and a source of generating 
foreign currencies. Similarly, in the Indian tourism industry, which is known for its traditional and cultural portfolio is soon becoming a favorable destination hub in Asia by attracting global tourists. It also creates employment opportunities mostly in the service sector. With the exponential increase in the population, more disposable income, enhanced lifestyle, world class business destination, and entrepreneurial activities, there lies an opportunity for enhancing nation's income. Despite having such vibrant tourism portfolio, Indian tourism is still largely unorganized because of the inadequacy of various institutional policies and planning. This lack of understanding to measure the potential of tourism, the Indian government, and various other stakeholders significantly squandered to collect revenue and failed to build a destination image. In this paper, an in-depth investigation has been carried out taking the Indian domestic tourism sector into account, especially on the market segmentation and classification problem based on stakeholder perspective. The tourism industry in India is growing rapidly. The present total market size of the tourism and hospitality industry in India stood at US\$ 117.7 billion in 2011 and it is expected to be US $\$ 418.9$ billion by 2022 (Source: Ministry of Tourism, Government Of India). With the increase in the number of tourists from different places of India, it has led many opportunities for small business and entrepreneurial ventures and consequently it calls for a challenge to understand the visitor behavior for tapping the potential opportunities by the tourism stakeholders. In this present competitive marketplace, it is of utmost importance to know the tourist profile and taste and provide them with customized traveling and tourism experience. For the same reason, in the marketing literature, the importance of segmentation in tourism to attract potential customers is firmly accepted and well utilized by the research community (Kastenholz, Davis, and Paul, 1999, Dolnicar and Leisch, 2004).The present study has been conducted to develop such a segmentation framework for profiling the visitors that would facilitate the decision makers and tourism stakeholders in providing better services.

\section{Literature Review and Problem Statement}

In the present scenario, tourism market segmentation has been evolved as a more prominent research area among the market researchers. Previous studies were more focused on destination specific, including various parts of the world, e.g., Canada (Carmichael and Smith, 2004), Spain (Molera and Albaladejo, 2007), Kenya (Beh and Bruyere, 2007), USA (Koh, Yoo and Boger, 2010), Scotland (Frochot 2005), France (Jang, Morrison and O'leary, 2004), Gambia (Rid, Ezeuduji and Pröbstl-Haider, 2014), Australia (Loker-Murphy, 1997), Finland (Pesonen, Laukkanen and Komppula, 2011), India (Mohsin and Ryan, 2007), etc. Apart from this, various research studies had been carried out to interpret the applicability of various segmentation bases for the different segment in tourism markets. Most of the studies in tourism research had employed the combination of three or four segmentation bases. The segmentation bases used in the various literature specific to the tourism sector have been highlighted in Table 1. Some of the researchers had preferred primary data collection while a few had assessed the data through the secondary source (Carmichael and Smith, 2004). The guideline to determine the appropriate sample size and, the number of variables had not been specified so far, but, in general, considering few variables and a collection of sample 5 to 10 times the number of variables had been recommended. The number of samples collected through a primary survey 
varied from 200 to 700; however, few researchers had collected more than 1000 data sample also, as explored in the literature (Johns and Gyimothy, 2002; Mohsin and Ryan, 2007; Oh, Uysal and Weaver, 1995; Ryan and Glendon, 1998). The preferred number of variables that had been employed to measure the tourist behavior ranges from 12 to 40 and, in the some cases; up to more than 50 variables (Oh, Uysal and Weaver, 1995; Johns and Gyimothy, 2002). The 5-Point and 7-Point Likert-type scales have been incorporated into the questionnaire. The output of segmentation studies (i.e. the list of factors and clusters) in the tourism sector includes, citing culture, rural, relax, novelty, etc., as the most crucial factors and, active, escapers, luxury seekers, etc., as the most useful clusters.

Table 1 Segmentation Surveys in Tourism Sector

\begin{tabular}{|c|c|c|c|c|c|c|}
\hline \multirow[t]{2}{*}{ Authors } & \multirow[t]{2}{*}{ Destination } & \multicolumn{5}{|c|}{ Segmentation Bases } \\
\hline & & Tourist sample & $\bar{D}$ & G & $\mathrm{P}$ & $\mathrm{B}$ \\
\hline Beh and Bruyere, 2007 & Kenya & 465 & Yes & Yes & Yes & Yes \\
\hline Carmichael and Smith, 2004 & Canada & $333428^{*}$ & Yes & & Yes & Yes \\
\hline Dolnicar, 2005 & Australia & 430 & Yes & Yes & & Yes \\
\hline Frochot, 2005 & Scotland & 734 & Yes & Yes & Yes & Yes \\
\hline Hsieh, O'Leary and Morrison, 1992 & Hong Kong & 807 & Yes & & & Yes \\
\hline Jang, Morrison and O'leary, 2004 & France & 496 & Yes & Yes & & Yes \\
\hline Johns and Gyimothy, 2002 & Denmark & 1099 & Yes & Yes & & Yes \\
\hline Kastenholz, Davis, and Paul, 1999 & Portugal & 187 & Yes & Yes & & Yes \\
\hline Kim and Jogaratnam, 2003 & USA & 514 & Yes & Yes & & Yes \\
\hline Koh, Yoo and Boger, 2010, 2003 & USA & 214 & Yes & & & Yes \\
\hline Mohsin and Ryan, 2007 & India & 1026 & Yes & Yes & Yes & \\
\hline Molera and Albaladejo, 2007 & Spain & 335 & Yes & Yes & & Yes \\
\hline Loker-Murphy, 1997 & Australia & 690 & Yes & Yes & Yes & Yes \\
\hline Oh, Uysal and Weaver, 1995 & Australia & 1030 & Yes & & Yes & \\
\hline Park and Yoon, 2009 & Korea & 252 & Yes & & Yes & \\
\hline Pesonen, Laukkanen and Komppula, 2011 & Finland & 195 & Yes & Yes & Yes & Yes \\
\hline Rid et al., 2014 & Gambia & 430 & Yes & & Yes & Yes \\
\hline Ryan and Glendon, 1998 & UK & 1127 & Yes & Yes & Yes & Yes \\
\hline Sarigollu and Huang, 2005 & Latin America & 265 & Yes & & Yes & Yes \\
\hline
\end{tabular}

*Secondary data source used

*D-Demographic, G-Geographic, P-Psychographic, B-Behavioral

India is a conglomerate of the myriad of beautiful historical monument, rich culture, spirituality, and diversity. The Indian tourism sector provides a range of specialized tourism products including cruises, adventure, medical, wellness, sports, eco-tourism, films, rural and religious tourism. The Indian physical landscape provides amidst geographical diversity, attractive beaches, 30 World Heritage Sites and 25 biogeographic zones. Currently, tourism sector contributed 6.8\% of Indian GDP and the number of domestic tourists' visits in India more than 1 billion and reported a growth rate of $19.6 \%$ in 2012 (Source: Make in India). This growth is expected to increase more in the coming years. Last few years, the government gives much attention to the domestic tourism sector in India. This year 2015, it is considered one of the major thrust areas and India government targets to achieve 1450 million of domestic tourists by the year 
of 2016-17 (Source: Ministry of Tourism, Govt of India). To accomplish such an ambitious mission, it is required successful destination marketing with a better decision in policies, and planning. Many countries around the world do research on domestic tourism. However, limited studies have been conducted in Indian domestic sectors, in spite of higher growth rate and huge opportunities (Madhavan and Rastogi, 2013).

Understanding of customer behavior is necessary and indispensable for successful destination marketing. It helps to market the products and services successfully, but it's also required to know who wants them, what they want and how can marketer reach to the potential customer. It is essential to have knowledge of their customer (Kotler, 2000; Aaker, 2001). As a tourism marketer, when you have customer, it is important to recognize what are the factors affecting their travel decisions, how marketer can make comfortable to their customer and also what are the factors marketer should consider for attracting their customer (Aaker, 2001). Customers want to feel the pleasant experience and as a marketer, it is important to establish a strong sense of comfort with their customer. It is a well-known marketing rule and a survival strategy that better knowledge of your customer directly associated with the better business growth (Kotler, 2000). Tourism stakeholders are the key marketer and solely responsible for successful destination marketing (Sheehan, Ritchie and Hudson, 2007). Each of the stakeholders tries to know their customer. This is the rich practice among the stakeholders. The process of gaining knowledge of insight of a customer is a complex and multidimensional problem and several stakeholders associated with it. Stakeholder plays a critical role in tourism development of the destination. Recent studies tried to find out how tourism stakeholders marketed their destination. In tourism literature strongly support that sharing knowledge among the stakeholder always enhanced the overall marketing process. In tourism market segmentation such work in the context of tourism stakeholder and domestic tourism sector highly desirable (Sautter and Leisen, 1999; Robson and Robson, 1996; Bhat and Gaur, 2012; Tkaczynski, Rundle-Thiele and Beaumont, 2009; Sheehan, Ritchie and Hudson, 2007; Bramwell and Sharman, 1999; Jamal and Getz, 1995).

In literature, Market segmentation always recognized as a powerful method to develop a strong customer relationship by means of providing exact product, services to their customer (Kotler, 2000). As the definition stated that, market segmentation is the process of grouping of similar customer, so companies can target and reach their potential customer with proper marketing mix strategy and through the campaign. The result of market segmentation is highly sensitive to the selection of the segmentation variables, and omission of the key variables will provide an alternative solution which may not reflect the mirror of the actual destination (Hair, Black, Babin, Anderson and Tatham, 2006). So, the process of selection of variables acknowledges as an important step to the marketer for effective market segmentation. Previous literature on tourism market segmentation research does not provide any conclusive result on the selection of segmentation variables and in most of the studies, selection of variables, mostly depends on the researcher's judgment (Tkaczynski, RundleThiele and Beaumont, 2009). However, recent research work endorses that tourism stakeholder perspective segmentation approach is more rational and appropriate for the same. Considering the previous studies that have assessed on visitor data, have a limited focus to appreciate which segmentation variables tourism stakeholders use to segment their markets. Researchers anticipate that the main reason for the failure to predict actual visitor behavior is the inappropriateness in choosing the segmentation variables followed in the 
existing academic approach (Tkaczynski, Rundle-Thiele and Beaumont, 2009). Beside of this, the further argument is that the customer has several needs, and it is difficult to fulfill all the need by one stakeholder. Hence, one set of segmentation variables cannot satisfy the business need of every stakeholder and maybe, the set of variables differs from one stakeholder to another stakeholder since the purpose and way of working of each of the stakeholders in the Indian domestic market are different and unique. Now the question will arise that what are variables stakeholder should consider for their business development? Which variables should include, or which variables should not include in the market segmentation process? Would the set variables vary or same from one stakeholder to another stakeholder? In case there is any difference, or is there any similarity or is there something where one stakeholder can help another stakeholder that will help to grow and mutually beneficial? So knowledge of such question always helpful to provide better understanding and formulation of appropriate marketing strategies and it is necessary to incorporate this entire concept in the research framework.

Hence, studies on stakeholder approach and their coordination will help tourism policy maker, tour operator and accommodation service providers to develop better policy, personalized to the needs of tourists, while taking advantage of the unique characteristics and resources available in their respective tourist regions. Due to these research gaps, this research work adopts a stakeholder perspective segmentation approach towards the market segmentation and classification of Indian domestic tourist. This study utilizes the existing academic knowledge and fusion with several stakeholders to explain the tourism behavior. Hence, our research focuses on the segmentation and classification of Indian tourists in the domestic sector, with the active involvement of stakeholder at each of the research steps. This paper tries to minimize the knowledge gap between academia and industry by using both side knowledge, and provide a strong and robust market segmentation and classification that are helpful for industrial people as well as contributing to the academic knowledge.

\section{Study objective}

The primary purpose this study is to explore the existing research concept of tourism market segmentation and provides a customize segmentation variables for each of the stakeholders. Especially the primary research objectives are as follows:

- To identify a broad range of travel variables to be used in domestic tourist market segmentation in India by three tourism stakeholders (i.e. Tour operator, tourism policy maker, accommodation service provider).

- To perform the segmentation studies on the basis of travel variables.

- To develop a predictive analytical tool to classify customers for three tourism stakeholders. 


\section{Methodology}

The following steps are considered in the research study as shown in Fig. 1. The detailed explanations of each step are dealt with in the following section.

\section{Data collection and Data description}

Indian domestic tourists have been considered for this study. The operational definition of 'Indian domestic tourists' taken for this study is a person who is Indian citizen would like to visit a place within India for at least one night for a holiday in the next 2 years (Tkaczynski, Rundle-Thiele and Beaumont, 2009). Respondents for this study came from different parts of India. The tool for data collection was Questionnaire surveys done offline and online. Convenience sampling method was used to only those people who were willing to respond were given the questionnaire (Kuo, Akbaria and Subroto, 2012). The data required for this study were collected through a self-administered structured questionnaires conducted between Feb and Aug 2014.

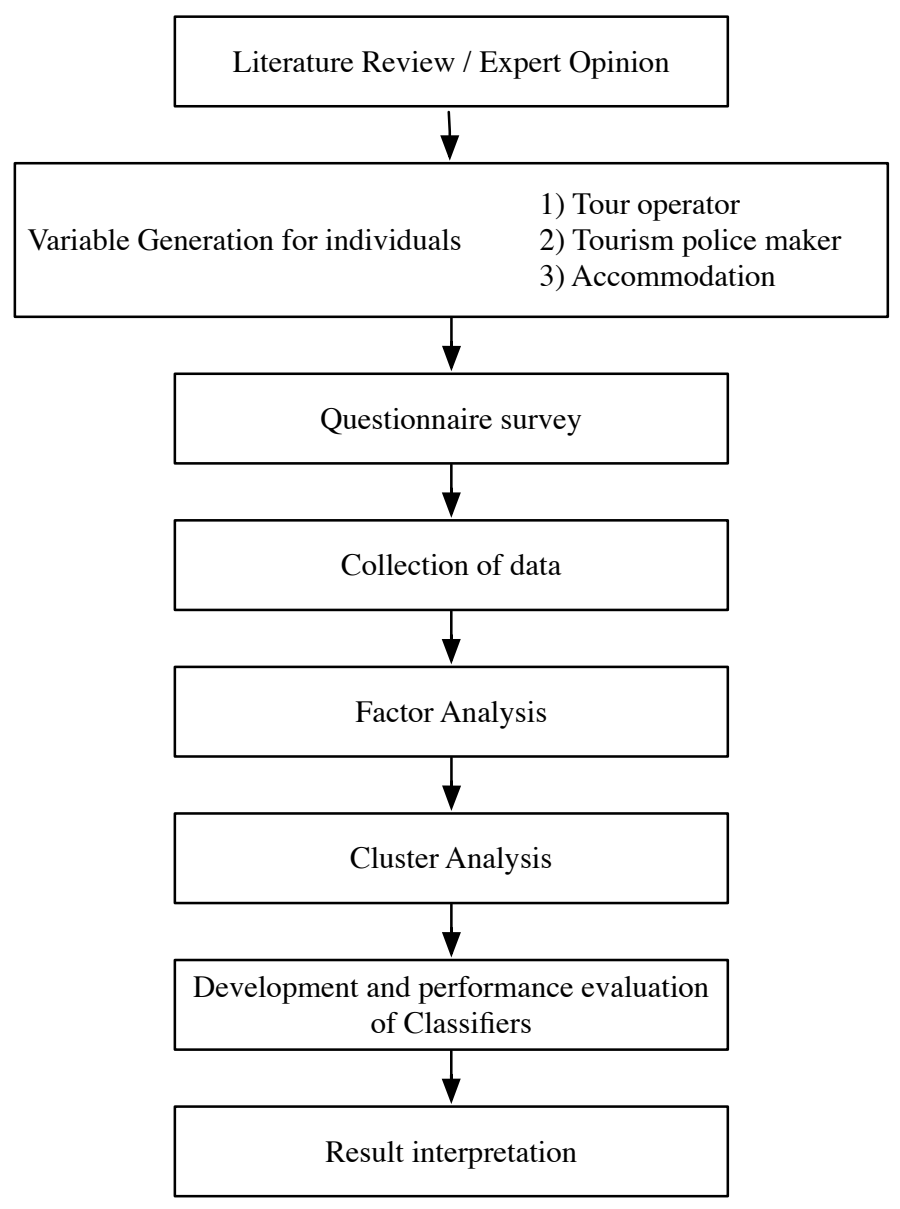

Fig. 1 Framework of Tourist Behavior Study 
Online and offline survey methods have been preferred as to reach every social, demographic profile and to make the sampling process as random as possible, in order to remove the pre-selection bias.

The variables employed in this research were identified from two sources - previous literature in the area, and semi-structured interviews with stakeholders. A case study based research approaches have been followed in this study as it is widely accepted procedure to" investigate complex issues" and to "understand marketing phenomena" (Yin, 2003). Twelve semi-structured interviews were performed with the stakeholders (that includes tour operators, accommodation service provider, Government tourism official) to understand their market segmentation process that has helped in the study to recognize relevant market segmentation variables. The main purpose of the interviews with stakeholders is to understand their business process, market, and the critical factor of their business that helps them to survive the competitive market. Interviewee profiles consisted of General Manager, director or assistant director level. The funnel approach based semi structure method was followed due to time constraints on the interviewee's part and also to get the maximum information out of it.

346 unique variables were identified from the literature review of previous research works and these were given to the stakeholders, who, after discussions and deliberations agreed on 105 variables, i.e. 37 variables accommodation service provider (Tan and Lo, 2008; Tsaur, Chiu and Huang, 2002; Wilensky and Buttle, 1988; Chung, Oh, Kim and Han, 2004; Bojanic., 2007; Ananth, DeMicco, Moreo and Howey, 1992), 34 variables tour operator (Frochot, 2005; Sarigollu and Huang, 2005; Molera and Albaladejo, 2007; Chand, 2010; Kastenholz, Davis and Paul, 1999; Kozak 2002; Oh, Uysal and Weaver, 1995; Beerli and Martm, 2004; Park and Yoon, 2009; Madhavan and Rastogi, 2013) and 32 variables tour policy maker (Oh, Uysal and Weaver, 1995; Kozak 2002; Chand, 2010; Narayan, Rajendran, Sai and Gopalan, 2009; Molera and Albaladejo, 2007; Sarigollu and Huang, 2005; Kastenholz, Davis and Paul, 1999), which were considered most important as followed by. The final questionnaire comprised of two parts - the first was about respondents' socio-demographic profile and the second aimed at incorporating respondent's opinion based on the significance of 105 variables converted into statements. A 5-point Likert-type scale with the interval scale ranging from 1 (Not at all important) to 5 (Extremely important) was used and 459 responses were collected for final analysis.

\section{Factor analysis, Cluster analysis}

The factor analysis method based on principal components analysis with varimax rotation was applied to explore the underlying factors or the latent variables from the observed variables. This methodological approach has been cited in tourism literature as a standard procedure to explore the dimensions from the the data of the visitors (Hair, Black, Babin, Anderson and Tatham, 2006). The following criteria were used in this study (1) factor loadings equal to or above 0.50, (2) Eigenvalues equal to or above 1.0 and (3) result of the factor analysis explaining at least $50 \%$ of the total variance (Hair, Black, Babin, Anderson and Tatham, 2006; Park and Yoon, 2009; Sarigollu and Huang, 2005). The main principle of factor analysis is to decompose a correlation matrix of measurable variables into its factor scores. After that factor score of each of the respondents were saved and used for further analysis. Data analysis of this study was carried 
out using SPSS 20 software.

The next step of the study follows the segmentation techniques applied to the heterogeneous population into the division of a homogeneous subgroup of similar behavior tourist. The K-means clustering technique is the most recommended method in tourism research, as it is easy to implement and robust in handling outlier. However, one of the drawbacks of clustering techniques is that the researcher needs to specify the number of required clusters. The decision of a number of clusters referred in the literature as "arbitrary decision" However, it depends on particular domain knowledge and requirement of the problem. For this reason, we followed suggested approach as mentioned in the literature to solve the same. We did hierarchical clustering based on ward-linkage method. The agglomerative coefficient value and dendrogram have been considered to identify the number of clusters, and the identified numbers of the cluster have given as an input of the K- means clustering.

\section{Classification}

A classification model is implemented for Indian domestic tourist for each of the stakeholders and the input to the classification model were the variables obtained from the stakeholders' responses. The classification models are developed and trained using the respective clustered groups as the desired group. In this study, 37, 34 and 32 measurable variables are considered as an input to the generalized classifier and, three, five and six nodes were considered as an output node of classifier because the input visitor data of Indian tourists was segmented into three, five and six distinct classes for each of stakeholder i.e. accommodation service provider, tour operator and tourism policy maker respectively. The classifier was trained using various algorithms and assess individual performance data on visitors for each of the stakeholders. After the completion of training of the classifier, the trained network served as an adaptive tourist classifier or decision support system for three tourism stakeholders. Ten classifiers have been developed, namely, Recursive Partitioning Trees, Pruning Recursive Partitioning Tree, Conditional Inference Tree, K-Nearest Neighbor Classifier, Naive Bayes Classifier, Radial basis function neural network classifier (RBF), Multilayer Perceptron Neural. Network classifier (MLP), Support Vector Machine (SVM), Linear Discriminant Analysis (LDA) and Random Forest. The study indicated that all the classifier model that were trained and their performances were also examined. Training data set is prepared by taking 70 percent of the total data and rest 30 percent of the data is used for testing the prediction performance of the classifier.

MLP and RBF are commonly known as adaptive classifiers, and fall under the category of artificial neural network (Haykin, 2002). LDA is a statistical classification technique and works based on the concept of maximizing the ratio of between-class variance to within-class variance. This class-specific type approach tries to maximize this ratio, so that sufficient class separability is obtained (Hair, Black, Babin, Anderson and Tatham, 2006). Naive Bayes Classifier and Random Forest are the probability based classifier where K-Nearest Neighbor Classifier is a non-parametric classifier (Han, Kamber and Pei, 2006). We developed another popular tree-based classification method, namely Recursive Partitioning Trees, Pruning Recursive Partitioning Tree, and Conditional Inference Tree. A classification tree uses the split condition to predict class labels based on one or multiple input variables build a tree-based classification model (Han, Kamber 
and Pei, 2006). Support Vector Machine (SVM) firmly based on the VC theory of statistical learning has been implied for pattern classification, but recently, has been modified for other applications, such as finding regression and distribution estimation (Suykens and Vandewalle, 1999). The principle of Kernel method based on cover's theorem can handle the complex non-linear data. This algorithm non-linearly transforms the data into higher dimensional feature space that is being able to separate the data linearly (Cristianini and Shawe-Taylor, 2000). The classifiers were implemented in R (CRAN, http://cran.r-project.org/) and IBM SPSS 20 software.

\section{Results and Disucussion}

Descriptive analysis shows that most of the respondents were male (62.1) compare to female (37.9). Sociodemographic characteristic of the sample is shown in the table 2. Most of the respondents were single (57.3), and they were predominantly young: $57.08 \%$ were age range between $18-34$ years, $34.20 \%$ were age range between 35-54 years. Only A Small Percentage of the respondents' age were above 55 years (8.7\%). Most of the respondents of the sample show the high level of education as about more than $93 \%$ respondents were having high school education and above. There was several respondents earned money less than INR 30000 per months $(52.93 \%)$ since most of them are student (39.21\%) and unemployed/housewives (14.59\%). The interesting point is that most of the respondents traveled more than once per year. Respondents were allowed to answer more than one choice in question on information access about accommodation, destination and travel companion. They preferred to obtain information about destination and accommodation from the Internet (86.06\%), friends/family (45.96\%) and Newspaper/TV channel (40.95\%) respectively. Respondents were like to visit with their friends $(73.85 \%)$ and family with children $(40.30 \%)$. It is noticeable that respondents are less preferred to consult with tour groups.

Before proceeding to the analysis, all variables were tested for modality and spread using a variety of statistical tests as suggested in previous literature (Johns and Gyimothy, 2002). It was concluded from test results and normal Q-Q plot that variable were justified to use parametric statistics. In the questionnaire 32, 34 and 37 variables were added to the principal component analysis, and the analysis was conducted separately for each stakeholder. Factor analysis extracted six; eight and six factors from, respectively, each of the stakeholder measurable variables, on the basis of Eigenvalue greater than one. The factor analysis results are shown in Table 3, Table 4 and Table 5.

In this study, the agglomerative hierarchical clustering with the ward method has been applied to the factor scores attained from factor analysis. The above process will cluster the Indian tourist based on their similarity in the behavior considering the Euclidean distance as the similarity measure between the data points. It is observed from the associated dendrogram and agglomerative scheduling that three, five and six cluster solution is possible respectively accommodation service provider, tourism policy maker, and tour operator. The results of ANOVA tests also confirmed that each of the factors having three stakeholders has contributed significantly while differentiating the given number of clusters. Additionally, the scheffe posthoc tests were conducted to check whether the given number of clusters has truly represented the statistical 
Table 2 Sodemographic Characteristics of Indian Domestic Tourist( $\mathrm{n}=459)$

\begin{tabular}{|c|c|c|}
\hline \multirow{2}{*}{$\begin{array}{l}\text { Variable } \\
\text { Sex }\end{array}$} & \multicolumn{2}{|c|}{ Frequency $(\%)$} \\
\hline & & \\
\hline . Female & 174 & 37.9085 \\
\hline · Male & 285 & 62.0915 \\
\hline \multicolumn{3}{|l|}{ Marital status } \\
\hline . Single & 263 & 57.29847 \\
\hline - Married & 196 & 42.70153 \\
\hline \multicolumn{3}{|l|}{ Age } \\
\hline$\cdot 18-34$ & 262 & 57.08061 \\
\hline$\cdot 35-54$ & 157 & 34.20479 \\
\hline$\cdot 55+$ & 40 & 8.714597 \\
\hline \multicolumn{3}{|l|}{ Education } \\
\hline · High school or less & 31 & 6.753813 \\
\hline - College & 143 & 31.15468 \\
\hline . University & 285 & 62.0915 \\
\hline \multicolumn{3}{|l|}{ Occupation } \\
\hline - Salaried worker & 188 & 40.95861 \\
\hline - Self employed & 24 & 5.228757 \\
\hline - Student & 180 & 39.21569 \\
\hline · Unemployed / Housewives & 67 & 14.59695 \\
\hline \multicolumn{3}{|l|}{ Income group } \\
\hline - Below Rs. 10000 per month & 63 & 13.72549 \\
\hline - Rs. $11000-20000$ per month & 120 & 26.14379 \\
\hline - Rs. $21000-30000$ per month & 60 & 13.0719 \\
\hline - Rs. 31000-40000 per month & 91 & 19.82571 \\
\hline - Rs. 41000 per month and above & 125 & 27.23312 \\
\hline \multicolumn{3}{|l|}{ Frequency of travel } \\
\hline - Less than 1 per year & 89 & 10.38998 \\
\hline . 1 per year & 93 & 20.26144 \\
\hline - More than 1 per year & 277 & 60.34858 \\
\hline \multicolumn{3}{|c|}{ Knowledge of destination and accommodation } \\
\hline - Through travel agent & 124 & 27.01525 \\
\hline · Through internet & 395 & 86.05664 \\
\hline - Through travel book & 155 & 33.76906 \\
\hline - Friend and family & 211 & 45.9695 \\
\hline · Newspaper / TV channel & 188 & 40.95861 \\
\hline \multicolumn{3}{|l|}{ Travelling companions } \\
\hline - With friends & 339 & 73.85621 \\
\hline - Couple & 86 & 18.73638 \\
\hline · Family with children & 185 & 40.30501 \\
\hline . Tour group & 31 & 6.753813 \\
\hline
\end{tabular}

significant distinct differences between the clusters with respect to the each of the factors. The above number of clusters is also tested with the managerial perspective since results should provide the effective market segmentation solution to the stakeholders. The typical criteria defined for effective segmentation in literature (Sarigollu and Huang, 2005) as

1. Consist of consumers with similar needs, attitude and marketing response, 
2. Segments are distinctly separable from each other and substantially large enough to be profitable for the long term.

3. Results are practical, usable and easily translated into a strategy.

Three, five and six cluster solution easily in favor of the above criteria and also corresponding cluster solution affirmed the statistical results.

Table 6 provides the information about the cluster center of each of the clusters. Maximum loading of the factor determines the name of each cluster. For each of the stakeholders, the names of the accommodation service provider are as follows, Convenience seeker tourist, Value seeker tourist, and Passive tourist. The names of the tourism policy maker are as follows, Passive tourist, Price-conscious rural life seeker, Safety-conscious religious life seeker, Information Seeker, Want-it-all seeker and Safety-conscious rural life seekers. The names of tour operator are as follows, Relaxers, Family togetherness seeker, Variety seeker, Culture/history seekers and Learners Tourist.

This session offers a brief description of each segment for each of stakeholder:

\section{Accommodation service provider}

\section{Segment 1: Convenience Seeker tourist}

The first segment identified by cluster analysis is defined as a Convenience Seeker tourist. This cluster comprises 136 respondents (or $29.6 \%$ of the total sample) and one of the smallest percentage of the three segments. This section consists of people who are more concerned about the security, quietness and convenience location of the hotel. They are fond to visit the hotel website and eager to receive promotions, discount, and tour information. They are well planned and sensitive towards the basic amenities provided by the hotel.

\section{Segment 2: Value Seeker tourist}

The second segment is labeled as Value Seeker tourist as they gave more emphasis on sales promotion, discount policy, the price of the accommodation and the food. This cluster comprises of 152 respondents (33.1\% of all samples).

\section{Segment 3: Passive tourist}

This cluster comprises 171 respondents (or $37.2 \%$ of the total sample) and one of the largest segments of this research work. This cluster has shown low priority in all the six factors. This result exhibited that most of the tourists plan their schedule without planning, or they are rarely bothered about accommodation part during pre plane schedule. It displays their sloppiness. They do not give much importance of staying as a part of their tour, and they are little bit unorganized.

\section{Tour operator}

\section{Segment 1: Relaxer}

This segment, defined as a relaxer and constitute of 91 respondents (or $19.8 \%$ of the total sample). 
This cluster exhibited a strong desire to visit for getting away from daily life or escapes from busy jobs. They also seek physical rest and feel the solitude.

Segment 2: Family togetherness

The next segment identified as family togetherness and consists of 121 respondents (or $26.4 \%$ of the total sample). The primary aim of this cluster is to spend good time with family and children. They are keen to know new places and do some adventure and fun. They also enjoyed shopping, sightseeing and activity with the family. They usually prefer to visit during festival time or near places during weekends.

Segment 3: Variety Seeker

The third segment identified by cluster analysis is characterized as variety seeker. They usually visit, a place to explore everything, including scenic beauty, general sightseeing, experience new thing, enjoying local customs and traditions, adventure and fun. Briefly, this segment of people seeks the taste of everything.

Segment 4: Culture/History seeker

This is the smallest segments nonetheless it consists of 33 respondents (or $7.2 \%$ of the total sample).This segment is labeled as culture/history and comprises of people who like to become deeply involved in the physical and emotional aspect of local customs and traditions. They are also interested to experience the new and exciting thing.

\section{Segment 5: Learners Tourist}

This is one of the largest segments and consists of 121 respondents (or $26.4 \%$ of the total sample). This segment comprises of people who are having a strong passion for enhancing their intellectual knowledge and experience the new destination and taste new foods. They are also keen interest in general sightseeing and entertain in luxury and shopping. This segment of people utilized travel as the best form of education.

\section{Tourism policy maker}

\section{Segment 1: Passive tourists}

This segment recognized as passive tourist and comprises of 35 respondents (or $7.6 \%$ of the total sample). This segment of people displayed less concern in all six factors. This small percentage of respondents clearly indicate the maturity of the Indian domestic tourism sector.

\section{Segment 2: Price-conscious rural life seeker}

The second segment identified by cluster analysis is defined as price-conscious rural life seeker tourist. This cluster constitute of 83 respondents (or $18.1 \%$ of the total sample). They are favored to visit economical and well-connected destination in terms of good infrastructure, easy transportation, availability of low budget accommodation and restaurant. They are also keen interest to spend time in rural life and taste the traditional food.

Segment 3: Safety-conscious religious life seeker 
This cluster comprises 133 respondents and one of the largest segments of this research work labeled as safety-conscious religious life seeker tourist. This segment consists of people who are strong concern about the safety and security of the place. They are generally accessed the facilities of the place such as health and banking services, high standard restaurants. They are eager to visit the religious site and try to involve emotionally. This result exhibited that a large section of tourists (or $29 \%$ of the total sample) is religious in nature, and they are highly conscious of safety, security and services available at the travel destination. It takes one of the major decision factors to select any destination.

Segment 4: Information seeker

This segment of people consisted of 66 respondents (or 14.4\% of the total sample) and labeled as Information seeker. They are inclined to visit a place where they easily access destination information from several sources like the information counter at the airport, hotel or tourist spot.

Segment 5: Want-it-all seeker

This segment identified by cluster analysis is recognized as want-it-all seeker tourist. This cluster comprises of 118 respondents (or $25.7 \%$ of the total sample). These segments of people are multifarious in nature and like to explore the destination fully. They favored to visit a place where they get a diverse taste, including culture, history, religious fulfillment, rural life, and nature while at the same time they are also worried about price, safety and security.

Segment 6: Safety-conscious rural life seeker

This is the smallest segments and consists of 24 respondents (or $5.2 \%$ of the total sample). They are an ardent lover of nature and rural life and at the same time they seek safety and comfort.

The next step of the research work was to develop a classification tool for each of the stakeholders in the context of Indian tourists. Table 7 shows a comparison of classification performance of different methods. The results indicate based on classification accuracy of the methods as shown in Table 7. The result exhibited that SVM performed better and reported $90.71 \%, 86.43 \%$ and $89.29 \%$ for accommodation service providers, tour operators and tourism policy makers respectively. The top three classifiers for accommodation service providers are as follows Support Vector Machine (90.71\%), Linear Discriminant Analysis (88.57), Multilayer Perceptron Neural Network classifier (87.86) and Naïve Bayes classifier (87.86). The top three classifiers for tour operator are as follows Support Vector Machine (86.43\%), Linear Discriminant Analysis (83.57\%) and Multilayer Perceptron Neural Network classifier (83.3\%). The top three classifiers for tourism policy maker are as follows Support Vector Machine (89.29\%), Linear Discriminant Analysis (86.42\%) and Radial Basis Function Neural Network classifier (83.37\%).

\section{Findings and Contribution}

There are several finding explored in this research study. First, It clearly indicates that people are attracted to a safety and comfort tourist place where location and security takes an important aspect of accommodation selection. Most of the travel information access by tourist from internet (89\%). So it is necessary for stakeholders, to make their visibility on the internet. Second, the result was affirmed that history, heritage, 
Table 3 Factor Loadings of the Variables, Eigen Values, Variance Explained and Cronbach's Value Obtained from Factor Analysis: For Tourism Policy Makers

\begin{tabular}{|c|c|c|c|c|}
\hline Factor & Factor loading & Eigen-Value & Variance explained & Cronbach's a \\
\hline Infrastructure and Affordable & & 5.683 & 17.079 & 0.951 \\
\hline $\begin{array}{l}\text { Inexpensive travel in destination } \\
\text { country }\end{array}$ & 0.961 & & & \\
\hline Budget accommodation & 0.875 & & & \\
\hline Inexpensive restaurant & 0.824 & & & \\
\hline Public transportation & 0.839 & & & \\
\hline $\begin{array}{l}\text { Condition of infrastructure at the } \\
\text { tourist spots }\end{array}$ & 0.880 & & & \\
\hline Accessibility of tourist spots & 0.861 & & & \\
\hline $\begin{array}{l}\text { Condition of infrastructure on the } \\
\text { way to tourist spots }\end{array}$ & 0.920 & & & \\
\hline Safety and Comfort & & 5.043 & 16.262 & 0.891 \\
\hline Warm welcome for tourists & 0.879 & & & \\
\hline Reliable weather & 0.678 & & & \\
\hline Warm and sunny climate & 0.845 & & & \\
\hline $\begin{array}{l}\text { Variety of short guided excur- } \\
\text { sions/tour }\end{array}$ & 0.513 & & & \\
\hline \multirow{2}{*}{$\begin{array}{l}\text { High quality restaurants } \\
\text { Security at the tourist } \\
\text { spots/places of visit }\end{array}$} & 0.536 & & & \\
\hline & 0.837 & & & \\
\hline $\begin{array}{l}\text { Safety of domestic travel (e.g. air- } \\
\text { lines, trains, buses, taxis, autorick- } \\
\text { shaws) }\end{array}$ & 0.707 & & & \\
\hline Personal guidance at tourist spots & 0.728 & & & \\
\hline Health service & 0.575 & & & \\
\hline Banking Service & 0.792 & & & \\
\hline $\begin{array}{l}\text { Religious and Emotional attrac- } \\
\text { tion }\end{array}$ & & 3.426 & 10.626 & 0.872 \\
\hline Feel emotionally involved & 0.808 & & & \\
\hline
\end{tabular}

Note: Variables were shown as per the results of factor analysis (eigenvalue $>1$ ) and factor loading $>0.5$. Kaiser-Meyer-Olkin measure of sampling adequacy $=.852$. Chi-square $=9127.038$. Bartlett's test of sphericity, $p<0.001$

rural and religious based tourist places are the most favorite destination place chosen by the domestic traveler. In this regards, price and safety of the destination are major concerned; therefore, the Indian government and collaboration with accommodation provider can arrange an economic package to promote the tourism in rural and religious places. Government can communicate with local police and as well as trained local young people as a special force and tour guide of that tourist destination. Third, infrastructure, accessibility and public transportation facilities of the tourist spot should be improved. Fourth, large segments of the tourist are passive in nature in the case of choosing accommodation in their travelling. The reason may be, they do not have access or unaware of information about the accommodation of the travel destination. Therefore, the Indian government, tour operator and accommodation provider should boost promotion channels by means of 
Table 4 Factor Loadings of the Variables, Eigen Values, Variance Explained and Cronbach's Value Obtained from Factor Analysis: For Tour Operators

\begin{tabular}{|c|c|c|c|c|}
\hline Factor & $\begin{array}{l}\text { Factor } \\
\text { loading }\end{array}$ & $\begin{array}{l}\text { Eigen- } \\
\text { Value }\end{array}$ & $\begin{array}{l}\text { Variance } \\
\text { explained }\end{array}$ & $\begin{array}{l}\text { Cronbach's } \\
\alpha\end{array}$ \\
\hline Escape/Relax & & 5.455 & 9.704 & 0.866 \\
\hline To get away & 0.817 & & & \\
\hline To relax & 0.855 & & & \\
\hline For physical rest & 0.855 & & & \\
\hline Escape from a busy job & 0.670 & & & \\
\hline Experience solitude & 0.574 & & & \\
\hline Sightseeing Variety/Activity & & 4.461 & 9.380 & 0.831 \\
\hline To observe scenic beauty & 0.797 & & & \\
\hline General sightseeing & 0.796 & & & \\
\hline Indulging in luxury & 0.744 & & & \\
\hline Shopping opportunities & 0.671 & & & \\
\hline Enjoy unique atmosphere & 0.606 & & & \\
\hline Culture/History & & 3.032 & 8.484 & 0.824 \\
\hline $\begin{array}{l}\text { Physically and emotionally immerse in the lo- } \\
\text { cal culture }\end{array}$ & 0.692 & & & \\
\hline Opportunities to enjoy arts and crafts & 0.827 & & & \\
\hline Enjoying ritual customs and traditions & 0.808 & & & \\
\hline Traveling to places historically important & 0.627 & & & \\
\hline Novelty/Entertainment & & 2.525 & 8.446 & 0.860 \\
\hline Novelty of experience & 0.952 & & & \\
\hline To do exciting things & 0.796 & & & \\
\hline Entertainment/nightlife & 0.797 & & & \\
\hline Visit to the site made you feel proud & 0.800 & & & \\
\hline Learning & & 2.411 & 8.237 & 0.813 \\
\hline Intellectual improvement & 0.694 & & & \\
\hline To attend cultural events & 0.683 & & & \\
\hline Seeing and experiencing a foreign destination & 0.713 & & & \\
\hline Learning new things, increasing knowledge & 0.618 & & & \\
\hline Trying new foods & 0.653 & & & \\
\hline Family togetherness & & 1.950 & 7.611 & 0.810 \\
\hline Opportunities for children & 0.742 & & & \\
\hline Having a good time with family & 0.925 & & & \\
\hline $\begin{array}{l}\text { Help my family learn more about religious cul- } \\
\text { ture }\end{array}$ & 0.719 & & & \\
\hline Spend more time with family & 0.795 & & & \\
\hline Convenience feature & & 1.248 & 7.380 & 0.788 \\
\hline Short travel distance & 0.942 & & & \\
\hline Religious interest & 0.735 & & & \\
\hline Festival time for vacation & 0.657 & & & \\
\hline Short duration in weekends & 0.780 & & & \\
\hline Adventure and Fun & & 1.036 & 5.812 & 0.711 \\
\hline To seek adventure and pleasure & 0.707 & & & \\
\hline Rediscovering myself & 0.754 & & & \\
\hline To have fun & 0.908 & & & \\
\hline Total variance extracted (\%) & & & 65.053 & \\
\hline Cronbach's $\alpha$ of all variables & 0.740 & & & \\
\hline
\end{tabular}

Note: Variables were shown as per the results of factor analysis (eigenvalue $>1$ ) and factor loading $>0.5$. Kaiser-Meyer-Olkin measure of sampling adequacy $=.801$. Chi-square $=7234.154$. Bartlett's test of sphericity, $p<0.001$ 
Table 5 Factor Loadings of the Variables, Eigen Values, Variance Explained and Cronbach's Value Obtained from Factor Analysis: For Tour Operators

\begin{tabular}{|c|c|c|c|c|}
\hline Factor & $\begin{array}{l}\text { Factor } \\
\text { loading }\end{array}$ & $\begin{array}{l}\text { Eigen- } \\
\text { Value }\end{array}$ & $\begin{array}{l}\text { Variance } \\
\text { explained }\end{array}$ & $\begin{array}{l}\text { Cronbach's } \\
\alpha\end{array}$ \\
\hline Escape/Relax & & 5.455 & 9.704 & 0.866 \\
\hline To get away & 0.817 & & & \\
\hline To relax & 0.855 & & & \\
\hline For physical rest & 0.828 & & & \\
\hline Escape from a busy job & 0.670 & & & \\
\hline Experience solitude & 0.574 & & & \\
\hline Sightseeing Variety/Activity & & 4.461 & 9.380 & 0.831 \\
\hline To observe scenic beauty & 0.797 & & & \\
\hline General sightseeing & 0.796 & & & \\
\hline Indulging in luxury & 0.744 & & & \\
\hline Shopping opportunities & 0.671 & & & \\
\hline Enjoy unique atmosphere & 0.606 & & & \\
\hline Culture/History & & 3.032 & 8.484 & 0.824 \\
\hline $\begin{array}{l}\text { Physically and emotionally immerse in the lo- } \\
\text { cal culture }\end{array}$ & 0.692 & & & \\
\hline Opportunities to enjoy arts and crafts & 0.827 & & & \\
\hline Enjoying ritual customs and traditions & 0.808 & & & \\
\hline Traveling to places historically important & 0.627 & & & \\
\hline Novelty/Entertainment & & 2.525 & 8.446 & 0.860 \\
\hline Novelty of experience & 0.952 & & & \\
\hline To do exciting things & 0.796 & & & \\
\hline Entertainment/nightlife & 0.797 & & & \\
\hline Visit to the site made you feel proud & 0.800 & & & \\
\hline Learning & & 2.411 & 8.237 & 0.813 \\
\hline Intellectual improvement & 0.694 & & & \\
\hline To attend cultural events & 0.683 & & & \\
\hline Seeing and experiencing a foreign destination & 0.713 & & & \\
\hline Learning new things, increasing knowledge & 0.618 & & & \\
\hline Trying new foods & 0.653 & & & \\
\hline Family togetherness & & 1.950 & 7.611 & 0.810 \\
\hline Opportunities for children & 0.742 & & & \\
\hline Having a good time with family & 0.925 & & & \\
\hline $\begin{array}{l}\text { Help my family learn more about religious cul- } \\
\text { ture }\end{array}$ & 0.719 & & & \\
\hline Spend more time with family & 0.795 & & & \\
\hline Convenience feature & & 1.248 & 7.380 & 0.788 \\
\hline Short travel distance & 0.942 & & & \\
\hline Religious interest & 0.735 & & & \\
\hline Festival time for vacation & 0.657 & & & \\
\hline Short duration in weekends & 0.780 & & & \\
\hline Adventure and Fun & & 1.036 & 5.812 & 0.711 \\
\hline To seek adventure and pleasure & 0.707 & & & \\
\hline Rediscovering myself & 0.754 & & & \\
\hline To have fun & 0.908 & & & \\
\hline Total variance extracted (\%) & & & 65.053 & \\
\hline Cronbach's $\alpha$ of all variables & & & & 0.740 \\
\hline
\end{tabular}

Note: Variables were shown as per the results of factor analysis (eigenvalue $>1$ ) and factor loading $>0.5$. Kaiser-Meyer-Olkin measure of sampling adequacy $=.852$. Chi-square=9127.038. Bartlett's test of sphericity, $p<0.001$ 
Table 6 Contributed Scores of Different Factors under Each Cluster for Three Stakeholders (Session 1)

\begin{tabular}{lcccc}
\hline Factors for & $\begin{array}{c}\text { Cluster I } \\
(n=136) \\
\text { Tourism }\end{array}$ & $\begin{array}{c}\text { Cluster II } \\
(2=152) \\
\text { policy maker }\end{array}$ & $\begin{array}{c}\text { Cluster III } \\
(n=171)\end{array}$ & F Value \\
\hline Basic amenities & $\mathbf{0 . 2 7 2 3 7}$ & -0.08529 & -0.14081 & $7.500^{* *}$ \\
Staff attitude and Services & 0.1924 & 0.10323 & -0.24478 & $8.736^{*}$ \\
Location and Security & $\mathbf{0 . 7 4 6 4 9}$ & -0.63213 & -0.0318 & $97.001^{*}$ \\
Price and Value & -0.71433 & $\mathbf{0 . 4 1 5 9}$ & $\mathbf{0 . 1 9 8 4 3}$ & $65.675^{*}$ \\
Reputation & 0.1951 & -0.25708 & 0.07335 & $8.329^{*}$ \\
Marketing and Promotion & $\mathbf{0 . 4 0 5 6}$ & $\mathbf{0 . 7 3 7 5 5}$ & -0.97818 & $323.570^{*}$ \\
\hline
\end{tabular}

Note: $1=$ Not at all important, $5=$ Extremely important.

$* p<0.001 * * p<0.005$

Cluster I : Convenience seeker tourist

Cluster II: seeker tourist

Cluster III: tourist

Table 7 Contributed Scores of Different Factors under Each Cluster for Three Stakeholders (Session 2)

\begin{tabular}{lccccccc}
\hline $\begin{array}{l}\text { Factors for } \\
\text { Tourism } \\
\text { policy maker }\end{array}$ & $\begin{array}{c}\text { Cluster I } \\
(n=35) \\
(7.6 \%)\end{array}$ & $\begin{array}{c}\text { Cluster II } \\
(n=83) \\
(18.1 \%)\end{array}$ & $\begin{array}{c}\text { Cluster III } \\
(n=133) \\
(29 \%)\end{array}$ & $\begin{array}{c}\text { Cluster IV } \\
(n=66) \\
(14.4 \%)\end{array}$ & $\begin{array}{c}\text { Cluster V } \\
(n=118) \\
(25.7 \%)\end{array}$ & $\begin{array}{c}\text { Cluster VI } \\
(n=24) \\
(5.2 \%)\end{array}$ & F Value \\
\hline $\begin{array}{l}\text { Infrastructure } \\
\text { and }\end{array}$ & 0.06889 & $\mathbf{0 . 4 8 8 3 9}$ & -0.66348 & -0.33542 & $\mathbf{0 . 5 5 9 5 9}$ & 0.05838 & $33.253^{*}$ \\
$\begin{array}{l}\text { Affordable } \\
\text { Safety and }\end{array}$ & -0.05445 & -1.32585 & $\mathbf{0 . 3 0 9 5 5}$ & -0.26628 & $\mathbf{0 . 6 9 9 5 3}$ & $\mathbf{0 . 2 4 2 1}$ & $85.659^{*}$ \\
$\begin{array}{l}\text { Comfort } \\
\text { Religious and } \\
\text { Emotional }\end{array}$ & 0.0141 & 0.15525 & $\mathbf{0 . 2 0 2 2 5}$ & -0.0106 & $\mathbf{0 . 2 2 2 0 2}$ & -2.74071 & $66.308^{*}$ \\
$\begin{array}{l}\text { attraction } \\
\text { Rural life and }\end{array}$ & -2.33496 & $\mathbf{0 . 3 1 6 4 8}$ & 0.12244 & -0.00155 & $\mathbf{0 . 2 8 8 5 9}$ & $\mathbf{0 . 2 1 7 4 7}$ & $78.141^{*}$ \\
$\begin{array}{l}\text { Nature } \\
\text { Information }\end{array}$ & -0.17588 & -0.43985 & -0.39338 & $\mathbf{1 . 6 6 8 2 4}$ & -0.09711 & -0.15262 & $86.029^{*}$ \\
$\begin{array}{l}\text { availability } \\
\text { History and }\end{array}$ & 0.03794 & $\mathbf{0 . 2 2 6 9 5}$ & -0.70616 & -0.05869 & $\mathbf{0 . 6 3 5 6 7}$ & 0.10912 & $31.746^{*}$ \\
\hline Heritage & & & & & & & \\
\hline
\end{tabular}

Note: $1=$ Not at all important, $5=$ Extremely important. $* p<0.001$

Cluster I : Passive tourist

Cluster II: Price-conscious rural life seeker

Cluster III: Safety-conscious religious life seeker

Cluster IV: Information seeker

Cluster V: Want-it-all seeker

Cluster VI: Safety-conscious rural life seekers

online presence, friends and family, and advertisement in newspaper/TV channel. Fifth, insights from data, it was clearly indicated that family togetherness and learner tourists are the two largest segments. These segments of people are fond of enjoyment; spend good time with family, adventure and fun. This research 
Table 8 Contributed Scores of Different Factors under Each Cluster for Three Stakeholders (Session 3)

\begin{tabular}{lcccccc}
\hline Factors for & $\begin{array}{c}\text { Cluster I } \\
\text { Tourism }\end{array}$ & $\begin{array}{c}\text { Cluster II } \\
(n=91)\end{array}$ & $\begin{array}{c}\text { Cluster III } \\
(n=121)\end{array}$ & $\begin{array}{c}\text { Cluster IV } \\
(n=33) \\
\text { policy maker }\end{array}$ & $\begin{array}{c}\text { Cluster V } \\
(n=121)\end{array}$ & F Value \\
\hline Escape/Relax & $\mathbf{0 . 5 2 0 6 7}$ & -0.02084 & $\mathbf{0 . 2 4 1 0 4}$ & -2.39565 & 0.09736 & $105.527^{*}$ \\
Sightseeing Variety/Activity & -1.38297 & $\mathbf{0 . 5 3 0 5 4}$ & $\mathbf{0 . 3 4 3 8 3}$ & -0.27728 & $\mathbf{0 . 3 2 0 9}$ & $118.666^{*}$ \\
Culture/History & -0.02807 & -0.31332 & $\mathbf{0 . 2 6 3 9 6}$ & $\mathbf{0 . 4 3 6 3}$ & 0.01256 & $6.479^{*}$ \\
Novelty/Entertainment & -0.1368 & 0.1091 & $\mathbf{0 . 3 0 8 0 7}$ & $\mathbf{0 . 2 6 1 1 7}$ & -0.31423 & $6.878^{*}$ \\
Learning & 0.04462 & $\mathbf{0 . 3 1 7 4 1}$ & -0.91959 & -0.30583 & $\mathbf{0 . 4 3 9 2 4}$ & $39.143^{*}$ \\
Family togetherness & 0.15069 & $\mathbf{0 . 6 4 1 1 3}$ & -0.33947 & $\mathbf{0 . 2 7 6 1 6}$ & -0.56886 & $33.425^{*}$ \\
Convenience feature & 0.16703 & $\mathbf{0 . 4 0 9 6 4}$ & -0.71448 & 0.00326 & 0.013 & $20.594^{*}$ \\
Adventure and Fun & 0.17212 & $\mathbf{0 . 5 7 3 8 1}$ & $\mathbf{0 . 2 4 8 9 3}$ & -0.09231 & -0.8694 & $49.988^{*}$ \\
\hline
\end{tabular}

Note: $1=$ Not at all important, $5=$ Extremely important. ${ }^{*} p<0.001$

Cluster I : Relaxers

Cluster II: Family togetherness seeker

Cluster III: Variety seeker

Cluster IV: Culture/history seekers

Cluster V: Learners Tourist

Table 9 Comparison of Classification Performance of Different Methods

\begin{tabular}{llll}
\hline Classifiers & $\begin{array}{l}\text { Accommodation } \\
\text { service } \\
\text { providers }\end{array}$ & $\begin{array}{l}\text { Tour } \\
\text { operators }\end{array}$ & $\begin{array}{l}\text { Tour } \\
\text { policy } \\
\text { makers }\end{array}$ \\
\hline Recursive Partitioning Trees & 75 & 55.71 & 59.29 \\
Pruning Recursive Partitioning Tree & 78.57 & 55 & 59.29 \\
Conditional Inference Tree & 75 & 61.43 & 75 \\
K-Nearest Neighbor classifier & 82.86 & 68.57 & 77.86 \\
Nä̈ve Bayes classifier & 87.86 & 77.86 & 79.29 \\
Multilayer Perceptron Neural Network classifier & 87.86 & 83.3 & 79.32 \\
Support Vector Machine & $\mathbf{9 0 . 7 1}$ & $\mathbf{8 6 . 4 3}$ & $\mathbf{8 9 . 2 9}$ \\
Linear Discriminant Analysis & 88.57 & 83.57 & 86.42 \\
Random Forest & 85.71 & 74.29 & 82.14 \\
\hline
\end{tabular}

work indicates in exploring what kind of decision variable domestic tourists have during their travelling in India. The result of this study further utilized for developing a decision support system for each of the stakeholders.

\section{Conclusions}

The main purpose of this research is to investigate the stakeholder involvement in their marketing strategies, variable selection and their individual viewpoint on market segmentation and classification. This study associated with three stakeholders and carried out in the domestic tourism sector. The results of this study identify the major factors that enhance their customer relationship and leads to the customer satisfaction. This present research work also implies several implications to each of the stakeholders in the context of 
Indian domestic tourism and also helpful to the destination marketing for better policy and promotional strategy. These results also supported the Indian government, national policy on the tourism that indicates on marketing and promotion efforts, the growth of online travel portals and growing intra- regional cooperation. This research works would also help in better understanding of tourism behavior and decision-making process considered by the domestic tourist during their travel planning. Although a late starter in promoting tourism for economic development, the Indian tourism industry has got tremendous potential in creating better services to its customers. The study showed that in this emerging globalized competitive market, where tourism sector constitutes an important part in the economic development, it is of utmost importance to know the tourist interest in better decision making and managerial implication by the stakeholders. The slogan of Indian tourism i.e. "Incredible India" can only become credible if it can provide a customized traveling destination space to its customers. For this, the Indian tourism industry needs decision makers to plan and frame tourism development policy. In this paper, the classification of Indian domestic tourists was examined based on three stakeholder perspective, namely tour operator and accommodation provider and tourism policy makers. This research work aimed to bridge the gap between the stakeholders and the tourist behavior for offering better services. As the present research consists of only three stakeholders, in the future study more stakeholders with large respondents can be incorporated. This research work would help the stakeholder in designing better-customized customer services and policies for enhanced overall tourism growth. Creating such avenues would not only attract domestic tourist, but the global tourist as well.

\section{References}

Aaker, D. A., 2001. Strategic Market Management. New York: John Wiley and Son

Ananth, M., DeMicco, F. J., Moreo, P. J. and Howey, R. M., 1992. "Marketplace Lodging Needs of Mature Travelers." The Cornell Hotel and Restaurant Administration Quarterly, Vol. 33, No. 4, pp. 12-24.

Beh, A. and Bruyere, B. L., 2007. "Segmentation by Visitor Motivation in Three Kenyan National Reserves." Tourism Management, Vol. 28, Issue 6, pp. 1464-1471.

Beerli, A. and Martin, J. D., 2004. "Factors Influencing Destination Image." Annals of Tourism Research, Vol. 31, Issue 3, pp. 657-681.

Bhat, S. and Gaur, S. S., 2012. "Managing Diverse Stakeholders in the Context of Destination Marketing." Worldwide Hospitality and Tourism Themes, Vol. 4, No. 2, pp. 185-202.

Bramwell, B. and Sharman, A., 1999. "Collaboration in Local Tourism Policymaking." Annals of Tourism Research, Vol. 26, Issue 2, pp. 392-415.

Bojanic, D. C., 2007. "Customer Profile of the "Carryou" Segment for Restaurants." International Journal of Contemporary Hospitality Management, Vol. 19, Issue 1, pp. 21-31.

Carmichael, B. A. and Smith, W. W., 2004. "Canadian Domestic Travel Behaviour: A Market Segmentation Study of Rural Shoppers." Journal of Vacation Marketing, Vol. 10, No. 4, pp. 333-347.

Chand, M., 2010. "A Cross-national Study of Motivational Determinants among Non-resident Indian Visitors to Religious Centers in India." International Journal of Hospitality and Tourism Administration, 
Vol. 11, No. 1, pp. 22-38.

Chung, K. Y., Oh, S. Y., Kim, S. S. and Han, S. Y., 2004. "Three Representative Market Segmentation Methodologies for Hotel Guest Room Customers." Tourism Management, Vol. 25, No. 4, pp. 429-441.

Cristianini, N. and Shawe-Taylor, J., 2000. An Introduction to Support Vector Machines and Other Kernelbased Learning Methods. Cambridge university press.

Dolnicar, S. and Leisch, F., 2004. "Segmenting Markets by Bagged Clustering." Australian Marketing Journal, Vol. 12, No. 1, pp. 51-65.

Frochot, I., 2005. "A Benefit Segmentation of Tourists in Rural Areas: A Scottish Perspective." Tourism Management, Vol. 26, Issue 3, pp. 335-346.

Han, J., Kamber, M. and Pei, J., 2006. Data Mining, Southeast Asia Edition: Concepts and Techniques. New Delhi, India: Morgan Kaufmann.

Hair, J. F., Black, B., Babin, B., Anderson, R. E. and Tatham, R. L., 2006. Multivariate Data Analysis (6th Edition). Upper Saddle River, NJ: Pearson Prentice Hall.

Haykin, S., 2002. Neural Networks. New Delhi, India: Pearson Education Asia

Hsieh, S., O'Leary, J. T. and Morrison, A. M., 1992. "Segmenting the International Travel Market by Activity." Tourism Management, Vol. 13, Issue 2, pp. 209-223.

Jamal, T. B. and Getz, D., 1995. "Collaboration Theory and Community Tourism Planning." Annals of Tourism Research, Vol. 22, Issue 1, pp. 186-204.

Jang, S., Morrison, A. M., and O'leary, J. T. (2004). A procedure for target market selection in tourism. Journal of Travel and Tourism Marketing, 16 (1), 19-33.

Johns, N. and Gyimóthy, S., 2002. "Market Segmentation and the Prediction of Tourist Behavior: The Case of Bornholm, Denmark." Journal of Travel Research, Vol. 40, Issue 3, pp. 316-327.

Kastenholz, E., Davis, D. and Paul, G., 1999. "Segmenting Tourism in Rural Areas: The Case of North and Central Portugal." Journal of Travel Research, Vol. 37, Issue 4, pp. 353-363.

Koh, S., Yoo, J. J. E. and Boger Jr, C. A., 2010. "Importance-performance Analysis with Benefit Segmentation of Spa Goers." International Journal of Contemporary Hospitality Management, Vol. 22, No. 5, pp. 718-735.

Kotler, P., 2000. Marketing Management. Prentice Hall, pp.172.

Kozak, M., 2002. "Comparative Analysis of Tourist Motivations by Nationality and Destinations." Tourism Management, Vol. 23, No. 3, pp. 221-232.

Kuo, R. J., Akbaria, K. and Subroto, B., 2012. "Application of Particle Swarm Optimization and Perceptual Map to Tourist Market Segmentation." Expert Systems with Applications, Vol. 39, Issue 10, pp. 8726-8735.

Loker-Murphy, L., 1997. "Backpackers in Australia: A Motivation-based Segmentation Study." Journal of Travel and Tourism Marketing, Vol. 5, No. 4, pp. 23-45.

Madhavan, H. and Rastogi, R., 2013. "Social and Psychological Factors Influencing Destination Preferences of Domestic Tourists in India." Leisure Studies, Vol. 32, Issue 2, pp. 207-217.

Make in India. Retrieved on 30 April, 2015. http://makeinindia.com/sector/tourism-hospitality/. 
Ministry of Tourism, Government of India. http://www.tourism.gov. in, retrieved on 30 April 2015.

Mohsin, A. and Ryan, C., 2007. "Exploring Attitudes of Indian Students toward Holidaying in New Zealand Using The Leisure Motivation Scale.” Asia Pacific Journal of Tourism Research, Vol. 12, No. 1, pp. 1-18.

Molera, L. and Albaladeo, I. P., 2007. "Profiling Segments of Tourists in Rural Areas of South-Eastern Spain." Tourism Management, Vol. 28, No. 3, pp. 757-767.

Narayan, B., Rajendran, C., Sai, L. P. and Gopalan, R., 2009. "Dimensions of Service Quality in Tourism — An Indian Perspective." Total Quality Management, Vol. 20, No. 1, pp. 61-89.

Oh, H. C., Uysal, M. and Weaver, P. A., 1995. "Product Bundles and Market Segments Based on Travel Motivations: A Canonical Correlation Approach." International Journal of Hospitality Management, Vol. 14, No. 2, pp. 123-137.

Park, D. B. and Yoon, Y. S., 2009. "Segmentation by Motivation in Rural Tourism: A Korean Case Study." Tourism Management, Vol. 30, pp. 99-108.

Pesonen, J., Laukkanen, T. and Komppula, R., 2011. "Benefit Segmentation of Potential Wellbeing Tourists." Journal of Vacation Marketing, Vol. 17, No. 4, pp. 303-314.

Rid, W., Ezeuduji, I. O. and Pröbstl-Haider, U., 2014. "Segmentation by Motivation for Rural Tourism Activities in The Gambia." Tourism Management, Vol. 40, pp. 102-116.

Robson, J. and Robson, I., 1996. "From Shareholders to Stakeholders: Critical Issues for Tourism Marketers." Tourism Management, Vol. 17, Issue 7, pp. 533-540.

Ryan, C. and Glendon, I., 1998. "Application of Leisure Motivation Scale to Tourism." Annals of Tourism Research, Vol. 25, No. 1, pp. 169-184.

Sarigollu, E. and Huang, R., 2005. "Benefits Segmentation of Visitors to Latin America." Journal of Travel Research, Vol. 43, Issue 3, pp. 277-293.

Sautter, E. T. and Leisen, B., 1999. "Managing Stakeholders - A Tourism Planning Model." Annals of Tourism Research, Vol. 26, No. 2, pp. 312-328.

Sheehan, L., Ritchie, J. B. and Hudson, S., 2007. "The Destination Promotion Triad: Understanding Asymmetric Stakeholder Interdependencies among the City, Hotels, and DMO." Journal of Travel Research, Vol. 46, Issue 1, pp. 64-74.

Suykens, J. A. K. and Vandewalle, J., 1999. "Least Square Support Machine Classifiers." Neural Processing Letters, Vol. 9, pp. 293-300.

Tan, A. Y. and Lo, A. S., 2008. "A Benefit-based Approach to Market Segmentation: A Case Study of an American Specialty Coffeehouse Chain in Hong Kong." Journal of Hospitality and Tourism Research, Vol. 32, Issue 3, pp. 342-362.

Tsaur, S. H., Chiu, Y. C. and Huang, C. H., 2002. "Determinants of Guest Loyalty to International Tourist Hotels - A Neural Network Approach.” Tourism Management, Vol. 23, Issue 4, pp. 397-405.

Tkaczynski, A., Rundle-Thiele, S. R. and Beaumont, N., 2009. "Segmentation: A Tourism Stakeholder View." Tourism Management, Vol. 30, Issue 2, pp. 169-175.

Wilensky, L. and Buttle, F., 1988. "A Multivariate Analysis of Hotel Benefit Bundles and Choice Tradeoffs." International Journal of Hospitality Management, Vol. 7, No. 1, pp. 29-41. 
World Travel and Tourism Council. Retrieved on 30 April, 2015.http://www.wttc.org.

Yin, K., 2003. Case Study Research - Designs and Methods (3rd ed.). California, USA: Sage Publications, Inc.. 